\title{
The epidemic characteristics, guidelines and policies: A compared analysis of literature between COVID-19 and SARS
}

Jing Li ( $\sim$ onlyjing2005@hotmail.com )

School of Public Health, Kunming Medical University

Jiayi Yang

the Children's Hospital Affiliated of Kunming Medical University

Kaili Wen

the Children's Hospital Affiliated of Kunming Medical University

Rong Lu

School of Public Health, Kunming Medical University

Xiaoliang Du

the Children's Hospital Affiliated of Kunming Medical University

\section{Systematic Review}

Keywords: COVID-19 or NCP, 2019-nCoV or SARS-CoV-2, SARS, Epidemic Characteristics, Strategies, Policies

Posted Date: February 28th, 2020

DOI: https://doi.org/10.21203/rs.3.rs-15311/v1

License: (c) (1) This work is licensed under a Creative Commons Attribution 4.0 International License. Read Full License 


\section{Abstract}

Background: COVID-19 broke out in Wuhan, and rapidly spread to other province of China and other countries. To understand epidemic characteristics, guidelines and policiesof COVID-19 compared to SARS, and further explore the gap of health system facing with major outbreaks for improvement in China.

Methods: A systematic review was performed using China academic literature (CNKI), Wan Fang, PubMed, medRxiv, bioRxiv,offical website of World Health Organization, National Health Commission of the People's Republic of China, the Hubei Province Health Commission, and Wuhan City Health Commission for literature of epidemiological and clinical characteristics, guidelines an policies of COVID-19 and SARS from 2003 to 2020 . Two dataset were obtained from the National Health Commission's open data information, and daily SARS epidemic section authorized by the State Council's Information Office.

Results: The 113 related studies finally entered final analysis, among which 63 were Chinese articles. Severe acute respiratory syndrome-associated coronavirus (SARS-CoV) and 2019 novel coronavirus (SARS-CoV-2) caused outbreak in 2002 and 2019 in China called SARS and 2019 coronavirus disease (COVID-19). Both belong to Beta Coronavirus ( $\beta-\mathrm{CoV})$. Their original cluster confirmed cases had contact history to wild animals, and clinical symptoms are similar. However, COVID-19 has a high human-to-human transmission capability, and more rapidly spread from Hubei province ( $97.9 \%$ cases) across China and over the world. R0 was estimated around 2.2 (1.4-3.8), and incubation period of COVID-19 is 1-14 days. Transmission routes predominantly have respiratory droplets, close contact and even air transmission by aerosols. A fatality rate was $2.70 \%(2004 / 74185)$ with the highest of $14.8 \%$ at over 80 years old, and cases mainly were males in the middle and elder ages. For prevention and control, strategies and policies consecutively were issued. Compared to those of SARS, responsiveness for COVID-19 is more prompt. Policy priorities tend to multi-sectors of cooperation, strong action to cut off source of infection (sealed Wuhan city),strengthening community prevention and mental health.

Conclusions: The major gap facing with epidemic outbreak exists in the weak health system especially public health system, although we already made a great progress and improvement in our preventive awareness. Therefore, we forcefully appeal to a strong public health system by government for continuous investment and improvement. An advanced public health system stands by us in times of peace, and while fights for us during epidemic outbreak period.

\section{Background}

Emerging infectious diseases predominantly threaten human health worldwide [1, 2]. Coronavirus (CoV) is a large family of zoonotic viruses that exist widely in nature. CoV belongs to the coronavirus family (Coronaviridae) with four genera from Alpha Coronavirus (a-CoV) to Delta Coronavirus ( $\delta$-CoV). Among them, Beta Coronavirus ( $\beta-\mathrm{CoV}$ ) is the most harmful to human beings [3, 4]. $\beta$ genus is divided into four subgroups A to D. Each of them has a different strain [5], which infects humans and animals causing host symptoms of respiratory, intestinal, liver and nervous system ranging from mild to severe. Three of severe acute respiratory syndrome-associated coronavirus (SARS-CoV), Middle East respiratory syndrome-associated coronavirus (MERS-CoV) and 2019 novel coronavirus (2019-nCoV) totally cause pneumonia of humans. Among them, two of them caused outbreak in 2002 and 2019 in China called SARS and 2019 coronavirus disease (COVID-19).

COVID-19 emerged in $12^{\text {th }}$ December 2019 in Wuhan; it promptly broke out in Wuhan in the early of January 2020; At the end of January 2020, it rapidly spread to other province of China and other countries. WHO announced that the novel coronavirus epidemic was listed as a public health emergency of international concern. Novel coronavirus was temporarily named as 2019-nCoV by World Health Organization (WHO) on 12 ${ }^{\text {nd }}$ January. After one month, WHO officially named novel coronavirus as SARS-CoV-2, and novel coronavirus pneumonia as COVID-19[6]. In China, COVID-19 was redistricted into Class $B$ infectious diseases, and prevented and controlled following with clauses of Class A infectious diseases in the Law [7] on January 20, 2020. Meanwhile, Chinese Center for Disease Control and Prevention (CCDC) carried out epidemic surveys at hierarchical levels across the country since $31^{\text {th }}$ December 2019. Other researches and development of SARS-CoV-2 vaccine are imperatively accelerated, separately. However, there is no specific anti-novel coronavirus drug, supportive treatments and molecular chemical drugs were provided into COVID-19 patients such as $\beta$-interferon Lopinavir and Ritonavir [8], GS-5734 and chloroquine [9], and targeted drugs related to angiotensin converting enzyme-2 (ACE2) [10]. The epidemic condition last, and there are still 72532 confirmed cases, 6242 suspected cases, 1872 deaths, 12972 recovery all over China at $18^{\text {th }}$ February 2020 [11]. Undoubtedly, it is more important to understand epidemic characteristics $₫$ guidelines and policies of COVID-19 compared to SARS for rapid response at the early epidemic stage. The purpose of this study is to comprehensively understand epidemic characteristics, guidelines and policies of COVID-19 compared to SARS, and further explore the gap of health system facing with outbreaks to close the gap in China.

\section{Methods}

\section{Research design}

A systematic review was performed from three aspects: epidemic characteristics, guidelines and policies among COVID-19 and SARS. The first part review was carried out using China academic literature (CNKI), Wan Fang, PubMed, medRxiv, bioRxiv and National Health Commission of the People's Republic of China for literature of epidemiological and clinical characteristics of COVID-19 and SARS from 2003 to 2020. The second part review was executed using official website of World Health Organization, National Health Commission of the People's Republic of China, the Hubei Province Health Commission, Wuhan City Health Commission for literature about guidelines, strategies and policies of COVID-19 and SARS from 2003 to 2020 . Thirdly, data of new cases of COVID19 and SARS by date were collected for improvement and further understanding the nature of two diseases in our systematic review.

\section{Searching strategy and data sources}


Web of Science databases above across the period 2003-2020 were used to identify relevant researches. Search terms used either singularly or in combination were "2019-nCoV", "Novel Coronavirus Pneumonia", "SARS", “NCP”, "SARS-CoV-2", "SARS-CoV”, "COVID-19", "guideline”, "policy" and "notice" in the thesaurus and index lists of the relevant databases in both Chinese and English words. Similarly, Manual searches of the bibliographies of searched articles and reviews in the field were also conducted. We included review, editorial, or methodological articles, news and comments related to our search terms. Additionally, data of COVID-19 were obtained from the National Health Commission's open data information, and SARS data from daily SARS epidemic section authorized by the State Council’s Information Office. Figure 1 showed the details of search and data collection strategy.

\section{Data management and Data analysis}

Data about new cases of COVID-19 and SARS were entered in Excel 2019. Data of COVID-19 was from 20 January to $20^{\text {th }}$ February in 2020 , and SARS from $20^{\text {th }}$ April 2003 to $27^{\text {th }}$ June 2003. Histograms were graphed by Excel 2019, and textboxes with codes of policies were finished in Word 2019. Then, textboxes were put into histograms, and finally saved as pictures. For literature review parts, thematic analysis of the content was undertaken using Ethnograph V6 software to assist with data management. Content analysis is the systematic examination of text and field notes by identifying and grouping themes.

\section{Results}

\section{Propagation sources of SARS-CoV-2 compared to SARS-CoV}

SARS-CoV-2 and SARS-CoV belong to the virus group $\beta$-coronavirus. SARS-CoV- 2 has $78 \%$ nucleotide homology with human SARS virus, about $50 \%$ homology with MERS virus [12,13]and more than $85 \%$ homology with bat-SL-CoVZC45 based on the phylogenetic tree of coronavirus [14]. Studies have shown that bats are natural hosts of more than 100 kinds highly pathogenic viruses, among which SARS-CoV is hosted in Chinese chrysanthemum-headed bat [15]. Maybe, it spreads from bat to humans due to evolutionary mutation [16] by intermediate hosts like pangolin [17]. The evidence about the transmission source came from original cluster confirmed cases with contact history to Seafood Market of Wuhan South China [18-21]. While, transmission pathway includes initial zoonotic (animal-to-human) transmission [22, 23] to secondary human-to-human transmission supported by increasing exportation cases of Wuhan across China fueled by human migration [24, 25]. Moreover, patients with asymptomatic infection and incubation infection maybe were potential important risk factors resulting in rapid spread [13]. Other study found that convalescent patients maybe also were contagious detected with SARS-CoV-2 [18]. We need further evidence on infectivity of latent and convalescent patients. In contrast, SARS might be an animal-borne infectious disease due to contact history with wild animal for the first case of SARS [26] and bats as a food ingredient for business transaction in Guangdong [26, 27]. Additionally, SARS-CoV emerged with high human-to-human transmission capability, characterized by family and medical staff infections [7]. Moreover, evidence about being capability of multiple and continuous human-to-human transmission of SARS-CoV came from one original patient resulting in at least four generations of cases. [28]

Certainly, both exist initial zoonotic transmission to secondary human-to-human transmission. There was evidence of SARS that a few cases highly had the ability of over-transmission with high contagiousness called "first" cases. However, there is lack of evidence about "first" case in outbreak of COVID-19, which suggests that 2019-nCoV is too insidious and fierce to difficultly track the chain of transmission. Additionally, there are two risk factors in COVID-19 for asymptomatic infection and incubation infection accelerating its rapid transmission (Table 1). Thus, the fight of prevention and control for COVID-19 should be tougher than SARS due to unclear propagation chain.

\section{Transmission route of COVID-19 compared to SARS}

Transmission routes of COVID-19 predominantly have respiratory droplets, close contact and even air transmission by aerosols [29]. Recently, SARS-CoV-2 was detected in the feces of confirmed cases in Wuhan, Shenzhen and the United States, indicating possibility of fecal-oral transmission [30, 31] due to virus replication and existence in digestive tract. Moreover, mother-to-child vertical transmission was supported by reports showed that cases presented positive nucleic acid in pharyngeal swabs 30 hours after birth [32]. At present, no evidence of virus mutation has been found [33]. Amounts of clinical isolates unrelated to time and geography are needed to assess the extent of viral mutations and whether these mutations indicate adaptability to human hosts [34]. People are generally susceptible to COVID-19 especially those who are low immune function, and children are no exception. In contrast, the route transmission of SARS includes respiratory transmission by close droplets and aerosols, and contact transmission through contaminated hands or even objects [35, 36]. SARS leads to outbreaks in hospitals and families due to close contact in a confined space [35, 37]. While, nosocomial infection is prominent. Additionally possibility of digestive tract transmission was found by indirect evidence that coronavirus RNA could be detected in the feces of patients with SARS [38]. Different nationalities are generally susceptible. In a word, transmission routes of both include droplets, close contact and even air transmission by aerosols, but mother-to-child vertical transmission was merely supported in COVID-19. Thus, COVID-19 almost covers all kinds of transmission routes, which has higher probability of propagation than SARS (Table 1).

\section{Dynamics of COVID-19 compared to SARS}

SARS-CoV-2 were highly contagious than SARS-CoV supported by estimated data of basic reproduction number $\left(\mathrm{R}_{0}\right)$ ranging from 2 to 6.5 [39-42]. Julien Riou et al found that $R_{0}$ was around 2.2 (1.4-3.8) indicating the potential for sustained human-to-human transmission [43]. Additionally, there were growing evidence of human-to-human transmission to support higher contagiousness than SARS-CoV and MERS-CoV [20, 44-47]. Generally, incubation period of COVID-19 is 1 -14 days [29]. At the early epidemic stage, mean incubation period was 5.2 days [48]. Other study showed that median incubation period was 4.75 days based on 4021 confirmed patients survey [49]. Contrastingly, there is limited literature to estimate dynamics of SARS, but one study showed that $\mathrm{R}_{0}$ 
was estimated from 2 to 4[50]. Although these evidences are based on different sample sizes, COVID-19 obviously has higher probability of propagation than SARS (Table 1).

\section{Incidence and fatality rate of COVID-19 compared to SARS}

Based on available data, fatality rate of COVID-19 in China was lower than SARS about $9.6 \%$ (774/8 098) [50]. Incidence line of COVID-19 was dynamic by time in the research with 72314 cases. Initially, new cases remained low and sporadic until $1^{\text {st }}$ January; there was an abrupt jump followed by an exponential growth until 23 January, and reached first incidence peak during $24^{\text {th }}$ and $28^{\text {th }}$ January, and then declined slowly [51]. During this period, an abnormal high value of one-day onset occurred on $1^{\text {st }}$ February. Since $3^{\text {rd }}$ February, the number of new cases has dropped for 15 consecutive days in China except Hubei Province [52]. Until 12 ${ }^{\text {nd }}$ February, 15152 new confirmed cases were reported nationwide (Figure 2). Among them, 97.9\% came from Hubei province [53]. For this incidence peak, the reason maybe was improvement of diagnosis standards, because Pneumonia Diagnosis and Treatment Program of Novel Coronavirus Infection (trial Fifth Edition) was issued adding clinical diagnosis to the case diagnosis classification in Hubei Province. Therefore, the number of clinical diagnosed cases was contributed into confirmed cases [54]. Crude fatality rate is the highest of $14.8 \%$ at over 80 years old group with higher fatality rate of males than females ( 2.8 vs. $1.7 \%$ ), followed by middle-aged group. Majority of them died due to complications. The infection risk possibly increased associated with the elder with underlying diseases such as asthma, diabetes and heart disease. Among children, the age range were from 30 hours to 17 years old [55]. Medical staff and family members of patients were at high risk of infection due to close contact [56, 57]. Supporting Data showed that the proportion of medical staff was $2.09 \%$ among 1099 COVID-19 cases from 552 hospitals in 31 provinces [58].

In contrast, more than $95 \%$ cases among 8273 were Chinese with fatality rate of nearly $10 \%$ among 775 deaths that clustered in those over 40 years old or with underlying diseases [5]. SARS stroked in winter and spring, and morbidity peak occurred in early February in Guangzhou and late April in other cities [59]. Based on the official issued data [60], new cases reached at the peak on $29^{\text {th }}$ April 2003, then consecutively decreased till to zero new case on $1^{\text {st }}$ June 2003 (Figure 2). In summary, incidence of COVID-19 is significantly higher than that of SARS, and while fatality rate across age groups of COVID-19 is lower that SARS based on cut-off study date. However, at over 80 years old group the fatality rate is the highest of $14.8 \%$. Thus, COVID-19 is characterized by higher incidence and moderate fatality rate than SARS.

\section{Gender and age distribution of COVID-19 compared to SARS}

Cases of COVID-19 mainly were males in the middle and elder ages. Among the first 425 COVID-19 patients, $56 \%$ were male with median age of 59 years old [48]. Another study on $2^{\text {nd }}$ January showed that 73\% (30/41) cases confirmed by laboratory also were men with median age of 49 (IQR: 41.0-58.0) years old [46]. Yang Yang et al study across China on $26^{\text {th }}$ January [49] suggested that people at all ages were generally susceptible, and those who were aged 30 to 65 years old accounted for $71.45 \%$ and children ( $<10$ years) for $0.35 \%$. While, incidence of male was higher than female $(0.31$ vs. 0.27 per 100000 , $P<0.001)$ among 4021 confirmed patients [49]. A study of 72314 cases [51] further confirmed that population is generally susceptible. $86.6 \%$ and $31.2 \%$ were those aged 30-79 and over 60 years old, separately. The ratio of diagnosed male to female was 1.06 .

In contrast, medical workers and retirees are highly at risk. While, proportion of medical staff reached $24.5 \%$ without gender difference [35]. Hospitals and families became the predominantly areas [61]. SARS occurred in any age groups focused on young and middle-aged group accounting for $80 \%$. However, elderly death cases accounted for $40 \%$ at the early stage of SARS, and fatality rate of the elder was significantly higher than other groups [62]. Severities of SARS were proportional to the amount and time of detoxification [62]. Those who had close contacts with patients were at the higher risk. Therefore冈the attacked population of COVID-19 focused on males in the middle and elder ages with those who had underlying diseases; while, SARS mainly attacked young and middle-aged group without significant sex difference. Both entirely put retirees and healthcare providers at the highest risk (Table 1).

\section{Region distribution of COVID-19 compared to SARS}

A total of 74185 confirmed cases and 2004 deaths of COVID-19 have been reported with a fatality rate of about $2.70 \%$ [11] in China on $18^{\text {th }}$ February 2020 . Majority of them were imported cases from Wuhan, and others were related to Wuhan [57]. Wuhan is one of the major transportation hubs in China with a population of more than 11 million. The spread of 2019-nCoV was accelerated due to population movement during the Spring Festival transportation. Promptly, COVID-19 disseminated across China. There was a positive correlation between numbers of confirmed cases and population mobility in Wuhan [10]. On January 15, 2020, CCDC confirmed the first known exported case of 2019-nCoV in the US state of Washington, who had recently returned from Wuhan City [63]. While, COVID-19 rapidly spread over the world. A total of 804 confirmed cases and 3 deaths have been reported in 25 countries except China with a case fatality rate of about $0.37 \%$ [64]. Contrastingly, SARS firstly was reported in 2002 in Shenzhen Guangdong Province. It last for almost eight months, and spread from Guangdong into 29 countries and regions around the world [19]. Summarily, Wuhan is the starting place of CoVID-19, and for SARS is Shenzhen. Both of two cities had history of contact with wild animals (Table 1).

\section{Clinical characteristics of COVID-19 compared to SARS}

Common clinical symptoms of COVID-19 were fever, fatigue and dry cough, and majority of severe cases developed into dyspnea or hypoxemia after one week and further rapid progression of acute respiratory distress syndrome, septic shock, and refractory metabolic [29]. Generally, symptoms of children are relatively mild. One study showed that severe and mild pneumonia accounted for $25.5 \%$ and $69.9 \%$, respectively. However, others suggested that majority of cases were mild to moderate reaching $80.9 \%$ [51]. There are partially different symptoms and chest imaging between severe/critical and mild patients. Moderate and low

Page $4 / 17$ 
fever or even no obvious fever occurred among severe/critical patients; low fever and mild fatigue without pneumonia among mild cases. In chest imaging, there were multiple small plaques and interstitial changes in the extra pulmonary zone at the early stage, and then multiple ground glass and infiltration shadow in both lungs for mild cases; In severe cases, lung consolidation is possible but pleural effusion were rare. Contrastingly, SARS outbreak characterized by atypical pneumonia with symptoms of fever, cough, headache, muscle pain, and respiratory infection [65]. Therefore, fever mainly is the starting symptom of both, and while severe and mild pneumonia is the predominant symptom with changes in lung imaging. However, symptoms of SARS was obviously severe than COVID-19 resulting in difficult diagnosis of COVID-19 (Table 1).

\section{Diagnosis criteria of COVID-19 compared to SARS}

Based on Diagnosis and treatment protocol of novel coronavirus pneumonia (Trial Version 6) [29], diagnosis criteria included suspected case and confirmed case. Criteria of suspected cases are those who have 1) COVID-19 epidemiological history, clinical manifestations with moderate or low fever and respiratory symptoms; 2) pulmonary imaging changes with small plaques shadow and interstitial changes or ground glass density shadows and infiltration shadow; 3 ) and blood routine changes with the total number of leukocytes in the early stage normal or decreased and lymphoid cells decreased. Meanwhile, diagnosis of confirmed case included that 1) detection of 2019-nCoV RNA was positive by photoluminescence RT-PCR technique of breath traces; or 2) blood samples and the gene sequence of detected virus in repertory tract or blood sample was highly homologous with the known gene of 2019-nCoV based on the diagnosis of suspected case. Totally, there are six versions of diagnosis and treatment protocol of NCP issued by National Health Commission of the People's Republic of China (NHC, PRC) as of $19^{\text {th }}$ February 2020. Among them, diagnosis criteria of the $5^{\text {th }}$ edition was different between Hubei province and other provinces in China, which added clinical diagnosis criteria. Fluorescence PCR technology has become the preferred screening method; however, the sensitivity of the existing novel coronavirus fluorescence PCR detection kit was low, and the detection rate was only $30-40 \%$ [66].

In contrast, based on Diagnosis and treatment protocol of Severe Acute Respiratory Syndrome(SARS) (2004 Edition), clinical diagnosis of SARS included those who 1) had SARS epidemiological features, corresponding clinical manifestations with fever exceeding $38^{\circ} \mathrm{C} ; 2$ ) respiratory symptoms and pulmonary $\mathrm{X}$-ray changes with ground glass density shadows and lung consolidation shadows; and 3) ruled out the diagnosis of other diseases. Laboratory diagnosis included that the secretion was positive for SARS-CoV RNA detection, or the serum (or plasma) SARS-CoV specific antigen N protein was positive, or the serum SARS$\mathrm{CoV}$ antibody was from negative to positive, or the antibody titer was increased more than four times.

Compared to the two diagnosis criteria, both of clinical diagnosis were supported by epidemiological history, clinical manifestations, and pulmonary imaging changes. While, the technique of laboratory diagnosis is significantly developed and advanced in COVID-19. However, early diagnosis rate of COVID-19 keeps low especially among asymptomatic infection patients and suspected cases during incubation period. it is more important to develop rapid and accurate differential diagnosis technique.

\section{Comparison of guidelines between COVID-19 and SARS}

Table 2 showed that there are 7 guidelines issued at the global level by WHO from $17^{\text {th }}$ to $31^{\text {st }}$ January [67-73], and while 23 guidelines at the Chinese national level from $20^{\text {th }}$ January to $22^{\text {nd }}$ February [74-95], and 13 ones at the local level from $26^{\text {th }}$ January to $20^{\text {th }}$ February during the period of prevention and control of COVID-19[96-108]. The first document named 2019 temporary guidance document for laboratory testing of suspected cases of new coronavirus infection focused on testing of NCP among suspected cases on $17^{\text {th }}$ January [73]. After three days, another document from WHO paid attention to home care and contact management for 2019-nCoV [72]. At the national level, Chinese government issued two documents in the laws on $20^{\text {th }}$ January, and they focused on health quarantine and management of infectious diseases [95]. After that, guidelines issued involved in prevention and control [74,83,89,94], diagnosis and treatment [75,76,81,84,90,93], laboratory biosafety [91], public transport [88], and psychological assistance hotline aspects [82]. Moreover, documents focused on the elderly key population and public areas $[78,79,80,86]$. In the local level, documents focused on technical guidance $[97,98,104,108]$, measures $[96,105,106]$, command and notice about prevention and control of COVID-19[99,100,101,102,103,107].

\section{Comparison of policies between COVID-19 and SARS}

Figure 2 and Table 3 showed the similarities and differences among strategies and policies between COVID-19 and SARS. Similarities between them reflected in 12 aspects, which involved in outbreak notification [109,110], laws and regulations [95,111], Ministry of Education Notice, leader adjustments, outbreak report, disposal of patients' remains [85], notice about medical staff, public health emergency, and laboratory management [91,112,113]. The first case of COVID-19 found on $16^{\text {th }}$ November was reported on $31^{\text {st }}$ December [109]. While, the first SARS case was reported after four months [110]. In the outbreak of SARS, technical guideline was issued, and the whole preventive and control plan was implemented which acted by multi-sectoral cooperation. Moreover, both were included in the People's Republic of China on the Prevention and Control of Infectious Diseases. Outbreaks are reported one day at a time, but it started after near five months from the first case on $20^{\text {th }}$ April 2003 for SARS and already carried out on $21^{\text {st }}$ January 2020 after two months. Meanwhile, all country entered in the state of public health emergency on $9^{\text {th }}$ May 2003 for SARS and on $20^{\text {th }}$ January 2020 for COVID-19, separately. Furthermore, multi-sectors of cooperation mainly involved in CCDC, Health commission, Ministry of Transport, Ministry of Education, and even People's Liberation Army of China. Faced with outbreaks, our whole country was united fighting COVID-19.

\section{Discussion}

Both of 2019-nCoV and SARS-CoV belong to Beta Coronavirus ( $\beta$-CoV), and exist initial zoonotic transmission to secondary human-to-human transmission. However, SARS-CoV had the clear the chain of transmission, and while 2019-nCoV is too insidious and fierce to difficultly track the chain of transmission.

Page 5/17 
Additionally, $\mathrm{R}_{0}$ of 2019-nCoV estimated was higher than that of SARS-CoV, and there are symptomatic infection patients and incubation infection in COVID19. The two had the similar transmission routes, predominantly including respiratory droplets, close contact and even air transmission by aerosols. COVID-19 still have mother-to-child vertical transmission route. Therefore, 2019-nCoV obviously has higher probability of propagation than SARS-CoV. While, COVID-19 rapidly spread to whole country even over the world.

COVID-19 is characterized by higher incidence than SARS; while the fatality rate of SARS was higher than COVID-19 nearly reaching $10 \%$. Additionally $\$ the population of COVID-19 focused on males in the middle and elder ages with those who had underlying diseases; while, SARS mainly attacked young and middle-aged group without significant sex difference. Both entirely put retirees and healthcare providers at the highest risk. Moreover, Wuhan is the starting place of CoVID-19, and for SARS is Shenzhen. Their original cluster confirmed cases had contact history to wild animals. Clinical symptoms are similar, but symptoms of SARS are more serious than COVID-19. Fever mainly is the starting symptom of both, and while severe and mild pneumonia is the predominant symptom with changes in lung imaging. Thus, symptoms of COVID-19 obviously was not typical than SARS resulting in difficult diagnosis of COVID-19. Compared to the two diagnosis criteria, both of clinical diagnosis were supported by epidemiological history, clinical manifestations, and pulmonary imaging changes. While, the technique of laboratory diagnosis is significantly developed and advanced in COVID-19. However, early diagnosis rate of COVID-19 keeps low especially among asymptomatic infection patients and suspected cases during incubation period. it is more important to develop rapid and accurate differential diagnosis technique. Finally, we faced with great challenge about COVID-19 in epidemic characters, clinical diagnosis and laboratory diagnosis. The fight of prevention and control for COVID-19 should be tougher than SARS.

Among guidelines, both of diagnosis and prevention are as the same as important when outbreak comes at the WHO level. At the national level, our government rapidly respond to prevention and control of COVID-19 in all aspects such as prevention and control, diagnosis and treatment, laboratory biosafety, public transport, and psychological assistance hotline aspects. Besides these, local governments issued documents that focused on technical guidance, measures, command and notice about prevention and control of COVID-19. For SARS, majorities of guidelines were issued at the national level focusing on laboratory diagnosis, prevention and control on hospital. There are lack of prevention and control of community, and more details of guidance. Obviously, we made a great progress in our awareness of health.

Certainly, guidelines are not enough because all of them need strong policies to support. When COVID-19 and SARS outbreak in China, majorities of policies were carried out separately. However, days from the first case of COVID-19 were obviously shorter than that of SARS indicating an obvious progress in public health system. Certainly, it was associated with epidemic characteristics of diseases because of COVID-19 with high contagiousness and outbreak period moved forward. While, responsiveness is more prompt faced with COVID-19 outbreak. It was supported by more policies and strategies just implemented in outbreak of COVID-19 such as national health commission acted with other departments, sealed Wuhan city as strong action, strengthening community management, and caring about mental health. Faced with outbreaks, our whole country was united fighting COVID-19. Therefore, there is a great progress and improvement in our health system. However, we invested amount of healthcare sources, activated emergency plans and fight it by multi-sections, COVID-19 is still pandemic in China and even in the world. It suggested that the epidemic condition of COVID-19 is enormously serious than SARS. More importantly, a titanic gap exists in our health system especially public health system.

\section{Conclusion}

Certainly, COVID-19 is extremely similar to SARS in 2003. Knowledge, epidemic patterns, lessons and even policies of SARS outbreak are appropriately valuable for responsiveness to COVID-19. Regretfully, majority of policies and strategies issued during SARS period cannot consecutively be implemented or carried out. Therefore, fragmented management patterns resulted in the weak public health system, which had no enough capability of rapid response to outbreaks at the early stage. Thus, COVID-19 is pandemic over a whole country even the whole world.

We already made a great progress for our public health system, and improvement in our preventive awareness. However, the major gap facing with epidemic outbreak exists in the weak health system especially public health system. Therefore, we forcefully appeal to a strong public health system by government for continuous investment and improvement. Undoubtedly, an advanced public health system stands by us in peaceful times, while and fights for us during epidemic outbreak period.

\section{List Of Abbreviations}

CoV: Coronavirus

$\beta$-CoV: Beta Coronavirus

SARS-CoV: severe acute respiratory syndrome-associated coronavirus

MERS-CoV: Middle East respiratory syndrome-associated coronavirus

2019-nCoV or SARS-CoV-2: 2019 novel coronavirus

COVID-19: 2019 coronavirus disease

\section{Declarations}

\section{Ethic approval and consent to participate}


The study was approved by Kunming Medical University. The study belongs to literature review, and it does not involve in consent to participate.

\section{Consent for publication}

Not applicable.

\section{Availability of data and materials}

The dataset without personal identification came from official website. The details are available in the Methods part.

\section{Competing Interests}

All authors declare that they have no conflicts of interest statement.

\section{Funding}

The literature review was supported by National Natural Science Foundation of China (81760617) and Yunnan Applied Basic Research Projects-Union Foundation (2017FE467[-011]). Neither foundation was involved in the study design; collection, analysis, interpretation of data; writing of the manuscript; nor decision to submit the paper for publication.

\section{Authors' Contributions}

$\mathrm{JL}$ conceived and designed the study; JL, JY and KW reviewed the literatures; each author interpreted the papers and contributed to writing the manuscript.

\section{Acknowledgements}

The authors are grateful to Global Health Institute, Wuhan University for facilitating the review and publication process. Special thanks for Dr. Hao Li for his insightful comments and support for publication.

\section{References}

1. Jones KE, Patel NG, Levy MA, Storeygard A, Balk D, Gittleman JL, Daszak P: Global trends in emerging infectious diseases. Nature 2008, 451(7181):990993.

2. Morens DM, Folkers GK, Fauci AS: The challenge of emerging and re-emerging infectious diseases. Nature 2004, 430(6996):242-249.

3. Corman VM, Muth D, Niemeyer D, Drosten C: Hosts and Sources of Endemic Human Coronaviruses. Adv Virus Res 2018, 100:163-188.

4. Cui J, Li F, Shi ZL: Origin and evolution of pathogenic coronaviruses. Nat Rev Microbio/ 2019, 17(3):181-192.

5. Su S, Wong G, Shi W, Liu J, Lai ACK, Zhou J, Liu W, Bi Y, Gao GF: Epidemiology, Genetic Recombination, and Pathogenesis of Coronaviruses. Trends Microbiol 2016, 24(6):490-502

6. alan LY, Cong L, Wenzheng Z, Ping Y: Epidemiological Characteristics of COVID-19, SARS and MERS and Their Prevention and Control Measures Herald of Medicine 1-14.

7. L L, Liu JJ, RH J, HJ L: The legal class B infectious disease - the 2019 novel coronavirus (2019-nCoV) infected pneumonia in Wuhan, China: a review. New Medicine 2020, 30(1):14-21.

8. Jin YH, Cai L, Cheng ZS, Cheng H, Deng T, Fan YP, Fang C, Huang D, Huang LQ, Huang Q et al: A rapid advice guideline for the diagnosis and treatment of 2019 novel coronavirus (2019-nCoV) infected pneumonia (standard version). Mil Med Res 2020, 7(1):4.

9. Wang M, Cao R, Zhang L, Yang X, Liu J, Xu M, Shi Z, Hu Z, Zhong W, Xiao G: Remdesivir and chloroquine effectively inhibit the recently emerged novel coronavirus (2019-nCoV) in vitro. Cell Res 2020

10. Bin-bin Y, ue-ling ZY: Epidemiology and treatment of novel coronavirus pneumonia (COVID-19) in children and adults. Journal of Xi'an Jiaotong University (Medical Sciences):1-10.

11. National Health Commission of the People's Republic of China. As of 24:00 on February 18, the latest situation of new coronavirus pneumonia http://www.nhc.gov.cn/xcs/yqtb/202002/8f2cfd17f4c040d89c69a4b29e99748c.shtml [2020-02-19]

12. Roujian L, Xiang Z, Juan L, Peihua N, Bo Y, Honglong W, Wenling W, Hao S, Baoying H, Na Z et al: Genomic characterisation and epidemiology of 2019 novel coronavirus: implications for virus origins and receptor binding. The Lancet 2020(Pre-publis).

13. Chan JF-W, Yuan S, Kok K-H, To KK-W, Chu H, Yang J, Xing F, Liu J, Yip CC-Y, Poon RW-S et al: A familial cluster of pneumonia associated with the 2019 novel coronavirus indicating person-to-person transmission: a study of a family cluster. The Lancet 2020(prepublish).

14. Chen Y, Liu Q, Guo D: Emerging coronaviruses: Genome structure, replication, and pathogenesis. J Med Virol 2020.

15. Fan Y, Zhao K, Shi ZL, Zhou P: Bat Coronaviruses in China. Viruses 2019, 11(3).

16. Zhou Wang WQ, Hu Ke (ed.): A Handbook of 2019-nCoV Pneumonia Control and Prevention. Hubei Hubei Science and Technology Press; 2019.

17. WWW.CHINANEWS.COM. South China Agricultural University: the strains isolated from pangolins were $99 \%$ similar to the novel coronavirus [http://energy.chinanews.com/gn/2020/02-07/9082115.shtml [2020-02-07]]

18. Wu F, Zhao S, Yu B, Chen YM, Wang W, Song ZG, Hu Y, Tao ZW, Tian JH, Pei YY et al: A new coronavirus associated with human respiratory disease in China. Nature 2020.

19. Mahase E: China coronavirus: what do we know so far? Bmj 2020, 368:m308. 
20. Paules Cl, Marston HD, Fauci AS: Coronavirus Infections-More Than Just the Common Cold. JAMA 2020.

21. Chen N, Zhou M, Dong X, Qu J, Gong F, Han Y, Qiu Y, Wang J, Liu Y, Wei Y et al: Epidemiological and clinical characteristics of 99 cases of 2019 novel coronavirus pneumonia in Wuhan, China: a descriptive study. Lancet (London, England) 2020.

22. Wu P, Hao X, Lau EHY, Wong JY, Leung KSM, Wu JT, Cowling BJ, Leung GM: Real-time tentative assessment of the epidemiological characteristics of novel coronavirus infections in Wuhan, China, as at 22 January 2020. Euro Surveill 2020, 25(3).

23. Center for Disease Control and Prevention. Coronavirus Disease 2019 (COVID-19) Situation Summary [https://www.cdc.gov/coronavirus/2019nCoV/summary.html [2020-02-22]]

24. National Health Commission of the People's Republic of China. Diognosis and treatment protocol for Novel Coronavirus Pmeumonia (Version 4) [http://www.nhc.gov.cn/jkj/s3577/202002/573340613ab243b3a7f61df260551dd4.shtml [2020-02-07]]

25. National Health Commission of the People's Republic of China. Diognosis and treatment protocol for Novel Coronavirus Pmeumonia (Trial version 5) [http://www.nhc.gov.cn/xcs/zhengcwj/202002/3b09b894ac9b4204a79db5b8912d4440.shtml [2020-02-05]]

26. Zhao GP: SARS molecular epidemiology: a Chinese fairy tale of controlling an emerging zoonotic disease in the genomics era. Philos Trans $R$ Soc Lond $B$ Biol Sci 2007, 362(1482):1063-1081.

27. Wang $\mathrm{M}$, Yan $\mathrm{M}, \mathrm{Xu} \mathrm{H}$, Liang W, Kan B, Zheng B, Chen $\mathrm{H}$, Zheng $\mathrm{H}, \mathrm{Xu} \mathrm{Y}$, Zhang $\mathrm{E}$ et al: SARS-CoV infection in a restaurant from palm civet. Emerg Infect Dis 2005, 11(12):1860-1865.

28. Chen Z, Zhang W, Lu Y, Guo C, Guo Z, Liao C, Zhang X, Zhang Y, Han X, Li Q et al: From SARS-CoV to Wuhan 2019-nCoV Outbreak: Similarity of Early Epidemic and Prediction of Future Trends. bioRxiv 2020:2020.2001.2024.919241.

29. National Health Commission of the People's Republic of China. Diognosis and treatment protocol for Novel Coronavirus Pmeumonia (Trial version 6) [http://www.nhc.gov.cn/yzygj/s7653p/202002/8334a8326dd94d329df351d7da8aefc2.shtml [2020-02-19]]

30. National Health Commission of the People's Republic of China. What is fecal - oral transmission? [http://www.nhc.gov.cn/xcs/nwwd/202002/f0ada96415be451a8863fbebde104a62.shtml [2020-02-08]]

31. Holshue ML, DeBolt C, Lindquist S, Lofy KH, Wiesman J, Bruce H, Spitters C, Ericson K, Wilkerson S, Tural A et al: First Case of 2019 Novel Coronavirus in the United States. N Engl J Med 2020.

32. CCTV.com. A baby was diognosed COVID-19 after birth of 30 hours, indicating that there may be vertical infection between mother and child [http://news.cctv.com/2020/02/05/ARTIBNDLKFslreOGo0FW6Geu200205.shtml [2020-02-05]]

33. Woo PC, Lau SK, Lam CS, Lau CC, Tsang AK, Lau JH, Bai R, Teng JL, Tsang CC, Wang M et al: Discovery of seven novel Mammalian and avian coronaviruses in the genus deltacoronavirus supports bat coronaviruses as the gene source of alphacoronavirus and betacoronavirus and avian coronaviruses as the gene source of gammacoronavirus and deltacoronavirus. J Virol 2012, 86(7):3995-4008.

34. Perlman S: Another Decade, Another Coronavirus. N Engl J Med 2020.

35. Peng G, He J, Lin J, Zhou D, Yu D, Liang W, Li L, Guo R, Luo H, Xu R: Preliminary investigation on Epidemiological characteristics of Infectious atypical pneumonia in Guangdong Province. Chin J Epidemiol 2003, 24(05):20-22.

36. Liu Z, Shen Z, He X, Huang R, Teng R, Ning F, Li X, Ding L, Lin C: Epidemiological analysis of an imported infectious atypical pneumonia in Beijing. Chin J Epidemiol 2003, 24(05):28-29.

37. Wang M, Du L, Zhou D, Di B, Liu Y, Qin P, Wu X, Chen X, Qiu J, Li Z: Preliminary study on Epidemiology, Prevention and Control of Infectious atypical pneumonia in Guangzhou. Chin J Epidemiol 2003, 24(05):23-27.

38. Wang F: Identification of infectious atypical pneumonia and its significance. Chin J Epidemio/2003, 24(05):14-16.

39. Read JM, Bridgen JR, Cummings DA, Ho A, Jewell CP: Novel coronavirus 2019-nCoV: early estimation of epidemiological parameters and epidemic predictions. medRxiv 2020:2020.2001.2023.20018549.

40. Tang B, Wang X, Li Q, Bragazzi NL, Tang S, Xiao Y, Wu J: Estimation of the Transmission Risk of 2019-nCov and Its Implication for Public Health Interventions. SSRN 2020.

41. Ai L: Modelling the epidemic trend of the 2019-nCOV outbreak in Hubei Province, China. medRxiv 2020:2020.2001.2030.20019828.

42. Liu T, Hu J, Xiao J, He G, Kang M, Rong Z, Lin L, Zhong H, Huang Q, Deng A et al: Time-varying transmission dynamics of Novel Coronavirus Pneumonia in China. bioRxiv 2020:2020.2001.2025.919787.

43. Riou J, Althaus CL: Pattern of early human-to-human transmission of Wuhan 2019-nCoV. bioRxiv 2020:2020.2001.2023.917351.

44. Wang C, Horby PW, Hayden FG, Gao GF: A novel coronavirus outbreak of global health concern. Lancet 2020, 395(10223):470-473.

45. J MV, Marion K, Neeltje vD, Debby vR, Emmie dW: A Novel Coronavirus Emerging in China - Key Questions for Impact Assessment. The New England journal of medicine 2020.

46. Chaolin H, Yeming W, Xingwang L, Lili R, Jianping Z, Yi H, Li Z, Guohui F, Jiuyang X, Xiaoying G et al: Clinical features of patients infected with 2019 novel coronavirus in Wuhan, China. Lancet (London, England) 2020.

47. Chan JF-W, Yuan S, Kok K-H, To KK-W, Chu H, Yang J, Xing F, Liu J, Yip CC-Y, Poon RW-S et al: A familial cluster of pneumonia associated with the 2019 novel coronavirus indicating person-to-person transmission: a study of a family cluster. The Lancet 2020.

48. Li Q, Guan X, Wu P, Wang X, Zhou L, Tong Y, Ren R, Leung KSM, Lau EHY, Wong JY et al: Early Transmission Dynamics in Wuhan, China, of Novel Coronavirus-Infected Pneumonia. N Engl J Med 2020.

49. Yang Y, Lu Q, Liu M, Wang Y, Zhang A, Jalali N, Dean N, Longini I, Halloran ME, Xu B et al: Epidemiological and clinical features of the 2019 novel coronavirus outbreak in China. medRxiv 2020:2020.2002.2010.20021675. 
50. World Health Organization. Consensus document on the epidemiology of severe acute respiratory syndrome (SARS)

[https://www.who.int/csr/sars/WHOconsensus.pdf?ua=1 [2003-11]]

51. Team TNCPERE: The epidemiological characteristics of an outbreak of 2019 novel coronavirus pneumonia (COVID-19) in China. Chin J Epidemio/ 2020, 41(2):145-151.

52. People's Daily. New cases outside Hubei Province declined for 15 consecutive days [https://baijiahao.baidu.com/s? id $=1658922752858629782 \& w f r=s p i d e r \& f o r=p c$ [2020-02-19]]

53. National Health Commission of the People's Republic of China. As of 24:00 on February 12, the latest situation of new coronavirus pneumonia [http://www.nhc.gov.cn/xcs/yqtb/202002/26fb16805f024382bff1de80c918368f.shtml [2020-02-13]]

54. people.cn. Why the new cases increased significantly in Hubei today? [http://society.people.com.cn/n1/2020/0213/c1008-31585222.html [2020-0213]]

55. Shen K, Yang Y, Wang T, Zhao D, Jiang Y, Jin R, Zheng Y, Xu B, Xie Z, Lin L et al: Diagnosis, treatment, and prevention of 2019 novel coronavirus infection in children: experts' consensus statement. World Journal of Pediatrics 2020.

56. National Health Commission, Ministry of human resources and social security, Ministry of finance. Measures to improve the working conditions of frontline medical personnel and to earnestly care about their physical and mental health

[http://www.nhc.gov.cn/renshi/s7746/202002/63b2473ed0cd44d8ae8f40757208839a.shtml [2020-02-11]]

57. National Health Commission of the People's Republic of China. Diognosis and treatment protocol for Novel Coronavirus Pmeumonia (Trial version 3 ) [ http://www.nhc.gov.cn/xcs/yqfkdt/202001/f492c9153ea9437bb587ce2ffcbee1fa.shtml [2020-01-23]]

58. Guan W-j, Ni Z-y, Hu Y, Liang W-h, Ou C-q, He J-x, Liu L, Shan H, Lei C-I, Hui DS et al: Clinical characteristics of 2019 novel coronavirus infection in China. medRxiv 2020:2020.2002.2006.20020974.

59. Koh D, Sng J: Lessons from the past: perspectives on severe acute respiratory syndrome. Asia Pac J Public Health 2010, 22(3 Suppl):132S-136S.

60. china.cn.com. Daily SARS epidemic [http://www.china.com.cn/chinese/zhuanti/feiyan/325381.htm ]

61. Li L, Liu JJ, RH J, HJ L: The legal class B infectious disease - the 2019 novel coronavirus (2019-nCoV) infected pneumonia in Wuhan, China: a review. New Medicine 2020, 30(1):14-21.

62. Luo H, Yu H, Ni D, Yin W, Gao L, Mo J, Yang W, Yan J, Liang G, Zeng G et al: Etiological study and on-the-spot investigation of Infectious atypical pneumonia. Chin J Epidemiol 2003, 24(05):6-9.

63. Koenig K, Bey CK, McDonald EC: 2019-nCoV: The Identify-Isolate-Inform (3I) Tool Applied to a Novel Emerging Coronavirus. Western Journal of Emergency Medicine: Integrating Emergency Care with Population Health 0(0):1-7.

64. World Health Organization. Coronavirus disease 2019 (COVID-19) Situation Report - 29 [https://www.who.int/docs/defaultsource/coronaviruse/situation-reports/20200218-sitrep-29-covid-19.pdf?sfvrsn=6262de9e_2 [2020-02-18]]

65. National Health Commission of the People's Republic of China. Diognosis and treatment protocol for Severe Acute Respiratory Syndrome (SARS) (2004 Edition) [http://www.nhc.gov.cn/yzygj/s3573/200804/8538589dd6e9475dab3f77fa0f69edf0.shtml [2005-05-25]]

66. xueqiu.com. Some views on the design of fluorescent PCR primer probes for novel coronavirus [https://xueqiu.com/5828850316/141844391?page=2 [2020-02-22]]

67. World Health Organization. Global surveillance of human infection with new coronavirus 2019. https://www.who.int/zh/emergencies/diseases/novelcoronavirus-2019/technical-guidance. [2020-1-31]

68. World Health Organization. Recommendations on the use of masks in community, home care and health care settings during an outbreak of the new coronavirus (2019-nCoV). https://www.who.int/zh/emergencies/diseases/novel-coronavirus-2019/technical-guidance. [2020-1-29]

69. World Health Organization. Clinical management of suspected severe acute respiratory infections caused by new coronavirus in 2019. https://www.who.int/zh/emergencies/diseases/novel-coronavirus-2019/technical-guidance. [2020-01-28]

70. World Health Organization. Risk communication and community engagement in the state of preparedness and response to the new coronavirus (2019nCoV) in 2019. https://www.who.int/zh/emergencies/diseases/novel-coronavirus-2019/technical-guidance. [2020-01-26]

71. World Health Organization. Infection Prevention and Control in Medical Institutions When Suspected of New Coronavirus Infection. https://www.who.int/zh/emergencies/diseases/novel-coronavirus-2019/technical-guidance. [2020-01-25]

72. World Health Organization. Home Care and Contact Management for Suspected New Coronavirus (nCoV) Infected Persons. https://www.who.int/zh/emergencies/diseases/novel-coronavirus-2019/technical-guidance. [2020-01-20]

73. World Health Organization. Laboratory tests for suspected cases of new coronavirus infection in 2019. https://www.who.int/zh/emergencies/diseases/novel-coronavirus-2019/technical-guidance. [2020-01-17]

74. National Health Commission of the People's Republic of China. [China Government Network] Notice of the State Council on the Joint Prevention and Control Mechanism of New Coronavirus Infection and Pneumonia Epidemics.

http://www.nhc.gov.cn/xcs/zhengcwj/202002/e6dad55e209a4a46b9f003cd06080997.shtml.[2020-02-22]

75. National Health Commission of the People's Republic of China. Notice of the General Office of the National Health and Health Commission on Issuing a New Coronavirus Pneumonia Prevention and Control Plan (Fifth Edition).

http://www.nhc.gov.cn/xcs/zhengcwj/202002/a5d6f7b8c48c451c87dba14889b30147.shtml.[2020-02-21]

76. National Health Commission of the People's Republic of China. Notice on Issuing a New Coronavirus Pneumonia Diagnosis and Treatment Plan (Trial Version 6). http://www.nhc.gov.cn/xcs/zhengcwj/202002/8334a8326dd94d329df351d7da8aefc2.shtml. [2020-02-19] 
77. National Health Commission of the People's Republic of China. Notice of the General Office of the National Health and Health Commission on Printing and Distributing Guidelines for the Use of Disinfectants. http://www.nhc.gov.cn/xcs/zhengcwj/202002/b9891e8c86d141a08ec45c6a18e21dc2.shtml. [2020-02-19]

78. National Health Commission of the People's Republic of China. Notice on Issuing Guidelines for Medical Treatment of Elderly in Elderly Institutions During the Prevention and Control of New Coronavirus Pneumonia.

http://www.nhc.gov.cn/xcs/zhengcwj/202002/c26a0ca4a58d47489c5781493b2ac624.shtml. [2020-02-17]

79. National Health Commission of the People's Republic of China. Notice regarding the issuance of guidelines for health protection in shopping malls and supermarkets during the epidemic of the new coronavirus pneumonia.

http://www.nhc.gov.cn/xcs/zhengcwj/202002/6a13deef74604f39a16390679d98283c.shtml. [2020-02-15]

80. National Health Commission of the People's Republic of China. Notice on Printing and Distributing Guidance on Operation and Management of Airconditioning and Ventilation Systems in Offices and Public Places During the Epidemic Period.

http://www.nhc.gov.cn/xcs/zhengcwj/202002/60b58b253bad4a17b960a988aae5ed92.shtml.[2020-02-01]

81. National Health Commission of the People's Republic of China. Notice on Issuing a New Coronary Virus Pneumonia Diagnosis and Treatment Plan (Trial Implementation of Revised Fifth Edition). http://www.nhc.gov.cn/xcs/zhengcwj/202002/d4b895337e19445f8d728fcaf1e3e13a.shtml. [2020-02-08]

82. National Health Commission of the People's Republic of China. Notice on Printing and Distributing the Guidance of the Psychological Assistance Hotline During the Prevention and Control of New Coronavirus Pneumonia.

http://www.nhc.gov.cn/xcs/zhengcwj/202002/f389f20cc1174b21b981ea2919beb8b0.shtml. [2020-02-07]

83. National Health Commission of the People's Republic of China. Notice of the General Office of the National Health and Health Commission on Issuing a New Coronavirus Pneumonia Prevention and Control Plan (Fourth Edition).

http://www.nhc.gov.cn/xcs/zhengcwj/202002/573340613ab243b3a7f61df260551dd4.shtml. [2020-02-07]

84. National Health Commission of the People's Republic of China. Notice on Issuing a New Coronavirus Infected Pneumonia Diagnosis and Treatment Plan (Trial Version 5). http://www.nhc.gov.cn/xcs/zhengcwj/202002/3b09b894ac9b4204a79db5b8912d4440.shtml. [2020-02-05]

85. National Health Commission of the People's Republic of China. Notice on Printing and Distributing the Guidelines for the Disposal of Remains of Patients with Pneumonia Infected by New Coronavirus (Trial). http://www.nhc.gov.cn/xcs/zhengcwj/202002/163c26a24057489dbf64dba359c59a5f.shtml. [2020-02-01]

86. National Health Commission of the People's Republic of China. Notice on Printing and Distributing Guidelines for Health Protection of Pneumonia Infected by New Coronavirus in Public Places. http://www.nhc.gov.cn/xcs/zhengcwj/202001/d9ae8301384a4239a8041d6f77da09b6.shtml. [2020-0131]

87. National Health Commission of the People's Republic of China. Notice on Issuing Guidance for Protecting People at Different Risks of New Coronavirus Infection and Guidelines for Using Pneumonia Masks to Prevent New Coronavirus Infection.

http://www.nhc.gov.cn/xcs/zhengcwj/202001/a3a261dabfcf4c3fa365d4eb07ddab34.shtml. [2020-01-31]

88. National Health Commission of the People's Republic of China. Notice on Issuing Technical Guidelines for Disinfection Operation of Public Transport. http://www.nhc.gov.cn/xcs/zhengcwj/202001/2152d180f15540039ccd3c79d660c230.shtml. [2020-01-29]

89. National Health Commission of the People's Republic of China. Notice of the General Office of the National Health and Health Commission on Printing and Distributing the Pneumonia Prevention and Control Plan for the New Coronavirus Infection (Third Edition).

http://www.nhc.gov.cn/xcs/zhengcwj/202001/470b128513fe46f086d79667db9f76a5.shtml. [2020-01-28]

90. National Health Commission of the People's Republic of China. Notice on Printing and Distributing Pneumonia Diagnosis and Treatment Plan for New Coronavirus Infection (Trial Version 4). http://www.nhc.gov.cn/xcs/zhengcwj/202001/4294563ed35b43209b31739bd0785e67.shtml. [2020-01-27]

91. National Health Commission of the People's Republic of China. Notice of the General Office of the National Health and Health Commission on Issuing Biosafety Guidelines for New Coronavirus Laboratories (Second Edition).

http://www.nhc.gov.cn/xcs/zhengcwj/202001/0909555408d842a58828611dde2e6a26.shtml. [2020-01-23]

92. National Health Commission of the People's Republic of China. Notice on Printing and Distributing New Guides for the Prevention and Control of New Coronavirus Infection in Medical Institutions (First Edition). http://www.nhc.gov.cn/xcs/zhengcwj/202001/b91fdab7c304431eb082d67847d27e14.shtml. [2020-01-23]

93. National Health Commission of the People's Republic of China. Notice on Printing and Distributing Pneumonia Diagnosis and Treatment Plan for New Coronavirus Infection (Trial Version). http://www.nhc.gov.cn/xcs/zhengcwj/202001/f492c9153ea9437bb587ce2ffcbee1fa.shtml. [2020-01-23]

94. National Health Commission of the People's Republic of China. New Coronavirus Infection Control Plan (Second Edition). http://www.nhc.gov.cn/xcs/zhengcwj/202001/c67cfe29ecf1470e8c7fc47d3b751e88.shtml. [2020-01-22]

95. National Health Commission of the People's Republic of China. http://www.nhc.gov.cn/xcs/zhengcwj/202001/44a3b8245e8049d2837a4f27529cd386.shtml. [2020-01-20]

96. National Health Commission of the People's Republic of China. [Shaanxi] Divisional and hierarchical management of epidemic prevention and control in our province. http://www.nhc.gov.cn/xcs/fkdt/202002/c8aab53283fa43e487adf5d07f84cc66.shtml. [2020-02-20]

97. National Health Commission of the People's Republic of China. [Guangdong] Our province formulates a series of special medical insurance reimbursement policies to relieve the worries of patients with new coronary pneumonia.

http://www.nhc.gov.cn/xcs/fkdt/202002/59f84273a1904a1faca7742f98cde955.shtml. [2020-02-19]

98. National Health Commission of the People's Republic of China. Guangdong Province Issues Guidance on Divisional Prevention and Control of Districts. http://www.nhc.gov.cn/xcs/fkdt/202002/a5640c61d0284a2fb560484aa3e324df.shtml. [2020-02-19]

Page 10/17 
99. National Health Commission of the People's Republic of China. [Tianjin] The General Office of the People's Government of Tianjin issued a notice on measures to protect and care for frontline medical staff in the prevention and control of new crown pneumonia.

http://www.nhc.gov.cn/xcs/fkdt/202002/783e160ee6da4534b3a90318d68f31e7.shtml. [2020-02-18]

100. National Health Commission of the People's Republic of China. [Hubei] Circular of Wuhan Municipal New Crown Pneumonia Epidemic Prevention and Control Command on Strict Public Place Epidemic Prevention and Control Measures.

http://www.nhc.gov.cn/xcs/fkdt/202002/36437525a0d54cf99d386972b83c0731.shtml. [2020-02-17]

101. National Health Commission of the People's Republic of China. [Hubei] Notice of Hubei Provincial New Coronavirus Infectious Pneumonia Prevention and Control Command on Strengthening the Closed Management of Urban Communities and Communities (Efangzhifa [2020] No. 52).

http://www.nhc.gov.cn/xcs/fkdt/202002/14bd4dd62aa546429be90416be250a8d.shtml. [2020-02-16]

102. National Health Commission of the People's Republic of China. [Hubei] Notice of the People's Government of Hubei Province on Further Strengthening the Prevention and Control of New Crown Pneumonia. http://www.nhc.gov.cn/xcs/fkdt/202002/5a5389da1fb44c7a909cc86582d9c4ab.shtml. [2020-02-16]

103. National Health Commission of the People's Republic of China. [Inner Mongolia] Inner Mongolia Autonomous Region, New Coronavirus Infection and Pneumonia Prevention and Control Command Circular No. 2020. http://www.nhc.gov.cn/xcs/fkdt/202002/b154f9a34db6432c8c48450edbf4f84c.shtml. [2020-02-14]

104. National Health Commission of the People's Republic of China. [Jilin] Interpretation of the Provincial Government's "Several Measures on Further Supporting the Fight Against the Pneumonia Epidemic of New Coronavirus Infection".

http://www.nhc.gov.cn/xcs/fkdt/202002/0ab5c92f16f84ea1ac696fa54490b9b1.shtml. [2020-02-11]

105. National Health Commission of the People's Republic of China. [Hubei] Improve the command mechanism in wartime and implement prevention and control measures. http://www.nhc.gov.cn/xcs/fkdt/202002/dddf7bb8fa8a44c78014a40e9f67962c.shtml. [2020-02-07]

106. National Health Commission of the People's Republic of China. [Hubei] Interim Measures for Prevention and Control of Pneumonia of New Coronavirus Infection in Wuhan (Full Text). http://www.nhc.gov.cn/xcs/fkdt/202001/7bde2706a5614338b106362ac161ddaa.shtml. [2020-01-30]

107. National Health Commission of the People's Republic of China. [Guangxi] Order of the Leading Group of the Leading Group for the Prevention and Control of Pneumonia of New Coronavirus Infection in Guangxi Zhuang Autonomous Region.

http://www.nhc.gov.cn/xcs/fkdt/202001/465946fb21bb4abaa45cdbdc50fccbf4.shtml. [2020-01-28]

108. National Health Commission of the People's Republic of China. [Gansu] "Pneumonitis prevention and control technology plan for new coronavirus infection in Gansu Province". http://www.nhc.gov.cn/xcs/fkdt/202001/6b38148a91cf4219b94192337cf2f2b7.shtml. [2020-1-26]

109. CHEN Yi-fan,CAO Guang-wen. Incidence trend of novel coronavirus (SARS-CoV-2) -infected pneumonia in China. Shanghai Journal of Preventive Medicine. 1-6

110. Xinsheng Fan ,Longgen Ying. Exploratory Spatial data Analysis of SARS outbreak in China. ADVANCES IN EARTH SCIENCE.2005(03):282-291.

111. National Health Commission of the People's Republic of China. http://www.nhc.gov.cn/xxgk/pages/viewdocument.jsp? dispatchDate=\&staticUrl=/zwgkzt/wsbysj/200804/19028.shtml\&wenhao=\%E6\%97\%A0\&utitle=\%E4\%B8\%AD\%E5\%8D\%8E\%E4\%BA\%BA\%E6\%B0\%91\%E5\% $01498 \&$ manuscriptld=19028.

112. National Health Commission of the People's Republic of China. http://www.nhc.gov.cn/xxgk/pages/viewdocument.jsp? dispatchDate=\&staticUrl=/zwgkzt/wsbysj/200805/35750.shtml\&wenhao=\%E6\%97\%A0\&utitle=\%E5\%8D\%AB\%E7\%94\%9F\%E9\%83\%A8\%E5\%85\%B3\%E4\%l 02040\&manuscriptld=35750.

113. National Health Commission of the People's Republic of China. http://www.nhc.gov.cn/xxgk/pages/viewdocument.jsp? dispatchDate=\&staticUrl=/zwgkzt/wsbysj/200804/29498.shtml\&wenhao=\%E6\%97\%A0\&utitle=\%E4\%BC\%A0\%E6\%9F\%93\%E6\%80\%A7\%E9\%9D\%9E\%E5\% $01971 \&$ manuscriptld $=29498$

\section{Tables}

Table 1 Comparisons of epidemic characteristics between COVID-19 and SARS 
Epidemic Lineage

Source

Age

Latent period

Case-fatality rate

R0

Human-to-human

transmission

Transmission

speed

Severity of illness

Propagation

Source of transmission

Route of

transmission

Population

susceptibility

Clinic

Fever and

associated

symptoms

Respiratory

symptoms

Imaging Early stage

Progressive stage
Bat (Rhinolophus sinicus)

$30-79(86.6 \%)$

1-14 days

$3.06 \%$

$1.4-2.5$

Confirmed

Faster

Milder

Weak, diarrhea in a few patients

Dry cough

Dyspnea or hypoxemia (about 1 week later)

Severe cases accompanied with ARDS, septic shock, refractory metabolic acidosis and bleeding and coagulation dysfunction.

Multiple small plaques shadow and interstitial changes, especially in the extra pulmonary zone.

Multiple ground glass density shadow and infiltration shadow in both lungs

$\beta$-coronavirus Group, with $78 \%$ genetic similarity

Bat

$20-60(85 \%)$

2-10 days

$9.60 \%$

$2-4$

Slower

Severer

Patient and invisible infected person

Droplet, aerosol and contact

People generally susceptible

Exceeding $38^{\circ} \mathrm{C}$ and lasting for $1-2$ weeks.

Headache, muscular soreness, malaise and diarrhea

Dry cough and less phlegm

Dyspnea or hypoxemia (6-12d later)

Severe cases accompanied with hyperventilation, polypnea and respiratory distress

Single small ground glass density shadow, especially in the inferior lobes of bilateral lungs

Multiple large ground glass density shadows, accompanied with lung consolidation shadows

Table 2 Guidelines between COVID-19 and SARS 
WHO

2020/1/17 2019 temporary guidance document for laboratory testing of suspected cases of new coronavirus infection

2020/1/20 Interim Guidance Document for Home Care and Contact Management for Suspected New Coronavirus $(\mathrm{nCoV})$ Infectors

2020/1/25 Interim Guidance Document on Infection Prevention and Control in Medical Institutions When Suspected of New Coronavirus Infection

2020/1/26 Risk Communication and Community Participation in the Preparation and Response to New Coronavirus (2019-nCoV) 2019

2020/1/28 Interim Guidance Document for Clinical Management of Suspected Severe Acute Respiratory Infections Caused by New Coronavirus in 2019

2020/1/29 Temporary guidance document on the use of masks in communities, home care and health care settings during an outbreak of the new coronavirus (2019-nCoV)

2020/1/31 Third edition of Interim Guidance Document on Global Surveillance of Humans Infected with New Coronavirus 2019

Country

2020/1/20 New coronavirus-infected pneumonia is included in the management of quarantine infectious diseases prescribed by the Frontier Health and Quarantine Law of the People's Republic of China

2020/1/20 New coronavirus-infected pneumonia is included in the Class B infectious diseases specified in the Law of the People's Republic of China on the Prevention and Control of Infectious Diseases, and measures for the prevention and control of Class A infectious diseases

2020/1/22 New Coronavirus Infection Control Plan (Second Edition)

2020/1/23 Diagnosis and treatment of pneumonitis caused by new coronavirus (trial version 3 )

2020/1/23 Guide to New Coronavirus Infection Prevention and Control in Medical Institutions (First Edition)

2020/1/23 New Coronavirus Laboratory Biosafety Guide (Second Edition)

2020/1/27 Diagnosis and treatment of pneumonitis caused by new coronavirus (trial version 4)

2020/1/28 New Coronavirus Pneumonia Prevention and Control Plan (Third Edition)

2020/1/29 Technical guide for disinfection operation of public transport

2020/1/31 Guidelines for the protection of people with different risks of new coronavirus infection and guidelines for the use of pneumonia masks to prevent new coronavirus infection

2020/1/31 Guidelines for the health protection of pneumonia caused by new coronavirus infections in public places

2020/2/1 Guidelines for the health protection of pneumonia caused by new coronavirus infections in public places

2020/2/5 Diagnosis and treatment of pneumonitis caused by new coronavirus (trial version 5)

2020/2/7 New Coronavirus Pneumonia Prevention and Control Program (Fourth Edition)

2020/2/7 Guidelines for psychological assistance hotline during prevention and control of new coronavirus pneumonia

2020/2/8 New Coronavirus Pneumonia Diagnosis and Treatment Plan (Trial Version 5 Revised)

2020/2/12 Guidelines for the operation and management of air-conditioning and ventilation systems in offices and public places during the new crown pneumonia epidemic

2020/2/15 Guidelines for health protection in shopping malls and supermarkets during the epidemic of new coronavirus pneumonia

2020/2/17 Guidelines for the elderly in elderly care institutions during the prevention and control of new coronavirus pneumonia

2020/2/19 Disinfectant Use Guide

2020/2/19 New coronavirus pneumonia diagnosis and treatment plan (trial version 6)

2020/2/21 New Coronavirus Pneumonia Prevention and Control Plan (Fifth Edition)

2020/2/22 "Guidelines for the Prevention and Control of Epidemic Situations in the Resumption of Work and Production in Enterprises and Institutions"

Local

2020/1/26 "Technical Plan for Prevention and Control of Pneumonia Infected by New Coronavirus in Gansu Province"

2020/1/28 Order of Command of the Leading Group for the Prevention and Control of Pneumonia of New
2003/5/12 Administrative Measures for the Research Laboratory of Infectious Atypical Pneumonia Virus

2003/5/12 "Administrative Measures for the Prevention and Control of Infectious Atypical Pneumonia"

2003/5/14 "Architecture Design Guidelines for Hospitals Treating Patients with Infectious Atypical Pneumonia"

2003/11/5 Technical Guidelines for Hospital Prevention and Control of Nosocomial Infectious Atypical Pneumonia (SARS)

2003/11/21 "Laboratory diagnostic procedures for infectious atypical pneumonia and influenza and other respiratory infectious diseases" 
Coronavirus Infection in Guangxi Zhuang Autonomous Region

2020/1/30 Interim Measures for the Prevention and Control of Pneumonia of New Coronavirus Infection in Wuhan City, Hubei Province

2020/2/7 Hubei Province Improves Wartime Command Mechanism and Implements Prevention and Control Measures

2020/2/11 Jilin Province "Several Measures on Further Supporting the Fight Against the Pneumonia Epidemic of New Coronavirus Infection"

2020/2/14 Inner Mongolia Autonomous Region New Coronavirus Infection Pneumonia Prevention and Control Command Notice

2020/2/16 Notice of the People's Government of Hubei Province on Further Strengthening the Prevention and Control of Epidemic Situation of New Coronary Pneumonia

2020/2/16 Notice of Hubei Provincial New Coronavirus Infectious Pneumonia Prevention and Control Headquarters on Strengthening Closed Management of Urban Communities

2020/2/17 Circular of the New Crown Pneumonia Epidemic Prevention and Control Headquarters of Wuhan City, Hubei Province on Strict Prevention and Control Measures of Epidemic Situation in Public Places

2020/2/18 Several measures of Tianjin to ensure and care for frontline medical staff in the prevention and control of new crown pneumonia

2020/2/19 Guidance issued by Guangdong Province

2020/2/19 Guangdong Province formulates a series of special medical insurance reimbursement policies

2020/2/20 Shaanxi Province implements district and hierarchical management for epidemic prevention and control

Table 3 Policies between COVID-19 and SARS 
Similarities First case

National

Outbreak

notification

Related laws

and

regulations
19

S1: Wuhan Municipal Health Commission notified the epidemic

2: The novel coronavirus pneumonia was included in the Class B infectious diseases stipulated in the Law of the People's Republic of China on the Prevention and Control of Infectious Diseases, and measures for prevention and control of Class A infectious diseases were adopted. Besides, novel coronavirus pneumonia was incorporated into the management of quarantine infectious diseases as stipulated in the Frontier Health and Quarantine Law of the People's Republic of China.

$2020 / 1 / 20$

Public

emergency

Laboratory

Management

Measures

Related

Leader

Adjustments

$2020 / 2 / 13$

63

S5: Ying Yong served as Secretary of the Hubei Provincial Party Committee and Wang Zhonglin served as Secretary of the Wuhan Municipal Party Committee

S7: Notice of Ministry of Human Resources and Social Security and Ministry of Finance and National Health Commission on the protection of medical staff and related staff infected with novel coronavirus pneumonia due to performance of their duties

Ministry of Education Notice

Disposal of patient's remains
$2020 / 2 / 1$
S6: Novel coronavirus pneumonia outbreak began to report daily

\section{$2002 / 11 / 16$}

2003/3/31 $136 \quad$ S1: Ministry of

Health announced the first outbreak

$2003 / 4 / 13 \quad 149 \quad$ S2: SARS listed in

statutory

infectious diseases of the Law of the People's Republic of China on Prevention and Control of Infectious Diseases

$2003 / 5 / 9 \quad 175$

S3: State Council announced implementation of "Emergency Regulations on Public Health Emergencies"

S4: Administrative Measures for the Research Laboratory of Infectious Atypical Pneumonia Virus

S5: Wang Qishan was Acting Mayor of Beijing, Gao Qiang was Party Secretary of the Ministry of Health, and Wu Yi was Minister of Health

$2003 / 4 / 20$

156 S6: Daily SARS outbreak began to report

2003/5/6 $172 \quad$ S7: "Injury

Insurance

Regulations" promulgated, and medical staff

should be treated with occupational injury during the treatment of patients

2003/4/18 $154 \quad$ S8: Postponed postgraduate reexamination until the end of May and all foreign students cannot leave school during May Day S9: The Ministry of Civil Affairs and the Ministry of Health issued a joint notice: requiring the remains of patients who died of infectious atypical pneumonia to be cremated on the spot in time
Differences

National level

Social dimension
$2020 / 1 / 21$

40

$2020 / 1 / 23$

$2020 / 1 / 30$

$2020 / 1 / 22$

$2020 / 1 / 23$

$2020 / 1 / 27$

$2020 / 1 / 28$

$2020 / 1 / 29$

2020/1/31

\section{Strategies/policies of COVID-19}

D1: National Health Commission and relevant departments jointly prevent and control the epidemic of novel coronavirus pneumonia

\section{D2: Take the Wuhan closure}

D3: Urgent Notice of General Office of the State Council on Organizing the Resumption of Production and Scheduling of Key Material Production Enterprises for D11 Epidemic Prevention and Control

41 D4: Prevention and Control Protocol for Novel Coronavirus Pneumonia (Version 2)

42 D5: Notice on Issuing Technical Guidelines of Prevention and Control for Novel Coronavirus Pneumonia (Version 1) in Medical Institutions

46 D6: Notice of General Office of National Health Commission on Issuing the Guidelines for the Use of Common Medical Protective Products in the Prevention and Control of Pneumonia Infected by New Coronavirus (Trial)

47 D7: Notice on prevention and control of epidemic situation of novel coronavirus infection in the elderly

D8: Notice on Issuing Technical Guidelines for Disinfection Operation of Public Transport

D9: Notice on Issuing Guidance for Protecting People at Different Risks of New Coronavirus Infection and Guidelines for Using Masks to Prevent Novel Coronavirus Pneumonia 


\begin{tabular}{|c|c|c|c|}
\hline & $2020 / 1 / 31$ & 50 & D10: Notice on Issuing Guidelines for Health Protection of Novel Coronavirus Pneumonia in Public Places \\
\hline & $2020 / 2 / 2$ & 52 & D11: Notice on prevention and control of pneumonia in children and pregnant women with new coronavirus infection \\
\hline & $2020 / 2 / 8$ & 58 & $\begin{array}{l}\text { D12: Notice on strengthening maternal disease treatment and safe midwifery during the prevention and control of novel } \\
\text { coronavirus pneumonia }\end{array}$ \\
\hline & $2020 / 2 / 18$ & 68 & $\begin{array}{l}\text { D13: Notice on Strengthening the Treatment and Management of Patients with Severe Mental Disorders during the Novel } \\
\text { Coronavirus Pneumonia Outbreak }\end{array}$ \\
\hline Community & $2020 / 1 / 25$ & 44 & D14: Notice on strengthening community prevention and control of pneumonia outbreaks of novel coronavirus \\
\hline & $2020 / 2 / 15$ & 65 & $\begin{array}{l}\text { D15: Notice regarding the guidelines for health prevention and protection in shopping malls and supermarkets during the } \\
\text { epidemic of novel coronavirus Pneumonia. }\end{array}$ \\
\hline
\end{tabular}

\section{Figures}

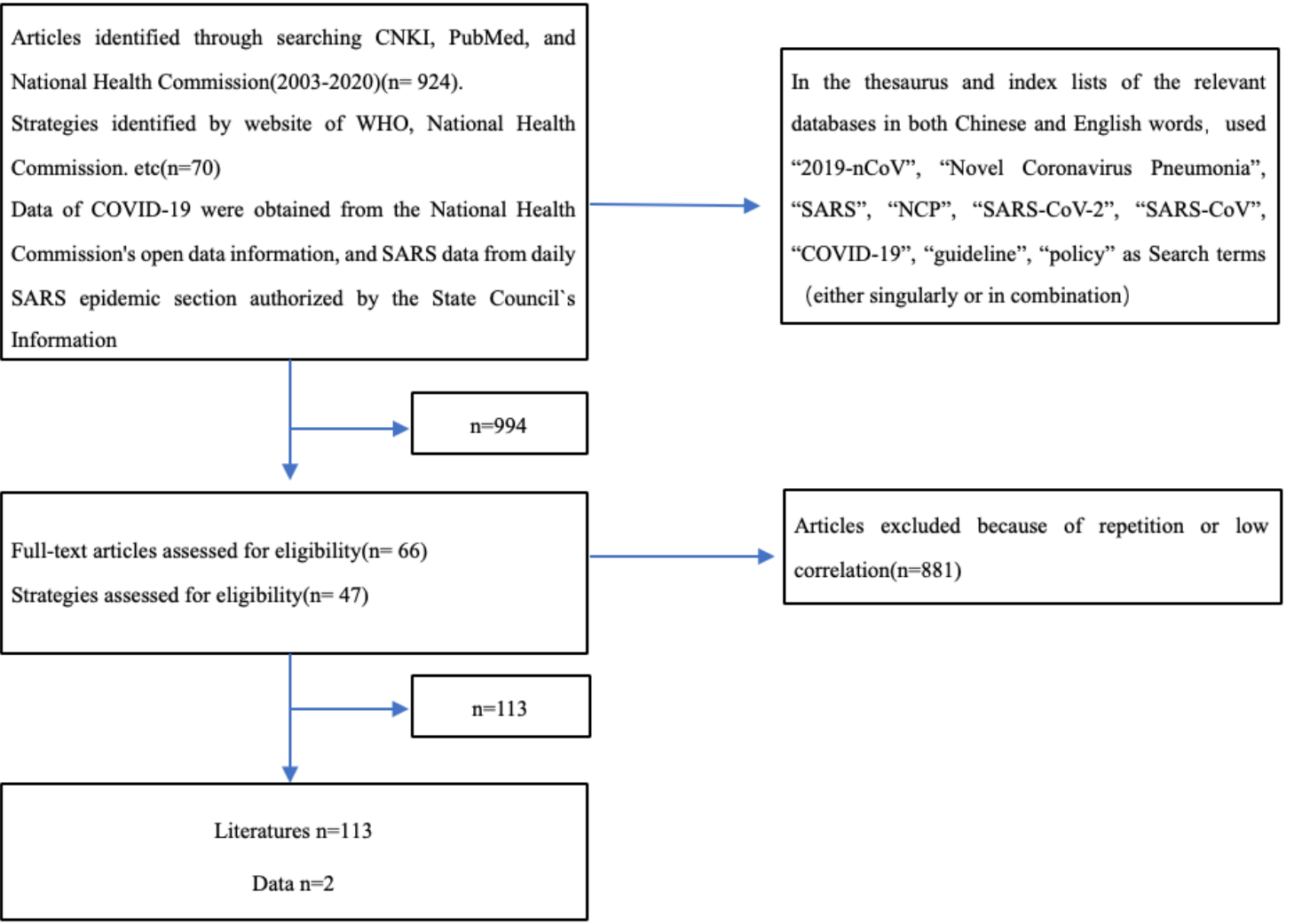

\section{Figure 1}

Flow chats of search and data collection strategy 


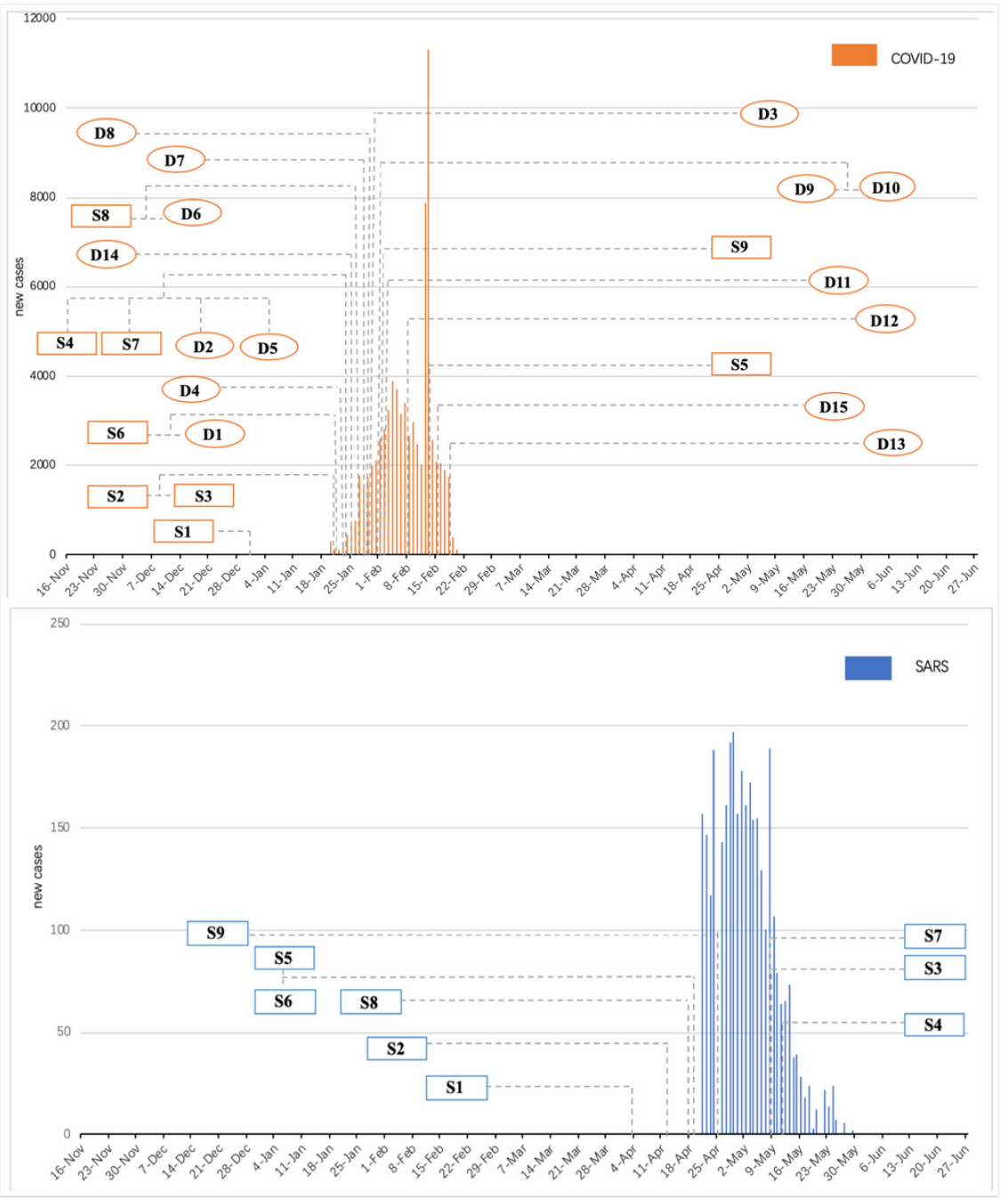

Figure 2

New cases and issued policies of COVID-19 and SARS by time 